
\title{
3 Research Square \\ Finite Element Analysis of Different Locking-Plate Fixation Methods for the Treatment of Ulna Head Fracture
}

\section{Yue Zhang}

Department of Traumatic Surgery, Shanghai East Hospital, Shanghai Tongji University School of Medicine

\section{Qin Shao}

Shanghai East Hospital

Chensong Yang

Shanghai East Hospital

\section{Changqing Ai}

Shanghai East Hospital

Di Zhou

Shanghai East Hospital

Yang Yu

Walkman biomaterial CO., LTD

Guixin Sun ( $\sim$ sunguixin@sina.com )

Shanghai East Hospital

\section{Research article}

Keywords: Finite element method, ulnar head fracture, locking plate fixation, distal radius and ulnar joint, internal fixation

Posted Date: November 3rd, 2020

DOI: https://doi.org/10.21203/rs.3.rs-99417/v1

License: (c) (i) This work is licensed under a Creative Commons Attribution 4.0 International License. Read Full License 


\section{Abstract}

Background: Ulnar head fractures are increasingly higher with the growing proportion of the elderly in the population. Failure to achieve stable anatomic reduction of ulna head fracture may lead to the DRUJ dysfunction and nonunion of distal radius. Due to the lack of the postoperative reporting outcomes and the biomechanical studies, it has not been well established about the optimal management of the comminuted distal ulna head fracture. This study aimed to explain the advantages and disadvantages of the ulnar-side locking plate fixation, compared with the dorsal-side one, and its screws arrangement in the treatment of the ulnar head fracture by using finite element analysis.

Methods: FE models of the ulnar head fracture and the models of ulnar-side locking plate and dorsal-side plate with two or three distal screws was constructed. In order to simulate forces acting on the ulnar and the osteosynthesis material during daily-life activity in subjects who underwent reconstructive surgery, we applied three loading conditions to each model, viz. axial compression $20 \mathrm{~N}, 50 \mathrm{~N}$, and torsion moments $1 \mathrm{Nm}$. Under these conditions, values of the von Mises Stress (VMS) distribution of the implant, peak VMS, and model displacement were investigated.

Results: Both the stress values and model displacement of ulnar-side plate were lower than those of dorsal-side plate. When adding a screw in the middle hole of the ulnar head, the values of model displacement and the peak stress in fixation system are lower, but it may evidently concentrate the stress on the middle screw.

Conclusions: In conclusion, our study indicated that plating locking plate on ulnar side had lower stress distribution on the plate and better stability than on dorsal side in ulnar head fracture fixation. Adding the additional screw on the ulnar head could reduce the displacement of the fixation system and increase the stability of the fixation system. This study requires clinical confirmation as to its practicality in the treatment of ulnar head fracture.

\section{Background}

Wrist joint is one of the main joints of a human body, which has high activity frequency. Previous studies suggested that the stability of the DRUJ(distal radius and ulna joint) greatly affected the function of wrist joint, not only for forearm rotation, but also for load and force transmission[1, 2]. If it is not treated in time, the fracture of DRUJ often leads to the occurrence of post-traumatic chronic pain and limitation of wrist joint activity, which causes great inconvenience to the work and daily life of patients. Ulna head fracture may be seen in up to $6 \%$ of patients with unstable fractures of the distal radius[3], which is increasingly higher with the growing proportion of the elderly in the population[4]. During past years, researchers suspected that the fracture of ulna head may cause nonunion of distal radius[5], instability of DRUJ and the decreased forearm rotation[6]. Failure to achieve stable anatomic reduction of ulna head fracture may also lead to the loss of ulnar variance and the distal ulna nonunion, thus may cause DRUJ dysfunction, ulnar- sided wrist pain, and post-traumatic arthrosis[5, 7-9]. 
Due to the lack of the postoperative reporting outcomes and the biomechanical studies[10], it has not been well established about the optimal management of the comminuted distal ulna articular head fracture. Ring et al.[11] reported the Condylar Blade Plate Fixation could achieve healing with good alignment, satisfactory function, and an acceptable rate of secondary surgery. David et al.[12] showed us the benefit of the application of a locked plate including the locked or fixed angle support, ability to insert variable lengths of locked pegs, and the low-profile design. But Dorsal locking plate may bring about the soft tissue complication[13]. Recently, distal ulna hook plate has been introduced for the treatment of distal ulna fractures, yet the limitation of the vertical arrangement of distal screws may result in instability of the construct $[14,15]$. In the present study, we found that ulnar side micro locking plate could achieve good outcomes. However, the distal radius fracture combined with ulnar head fracture is not a common clinical case and the application of ulnar side locking plate has never been reported before. Since the number of cases is relatively small, it becomes indispensable to apply finite element analysis to evaluate the mechanical properties of implants.

Therefore, the purpose of this study is to explain the advantages and disadvantages of the ulnar-side locking plate fixation, compared with the dorsal-side one, and its screws arrangement in the treatment of the ulnar head fracture by using finite element analysis.

\section{Methods}

\section{Establishment of the finite element models}

A 45-year-old healthy female volunteer was recruited without the history of wrist and systemic diseases. A Canon Aquilion ONE ViSION Edition CT scanner was used to perform a high-resolution CT scan of her right forearm. The scanning layer thickness was $0.5 \mathrm{~mm}$. The CT scan was stored as a DICOM format file into the Mimics 19.0. The reconstruction slice thickness was $0.5 \mathrm{~mm}$. The 3D model of the right forearm was obtained based on the gray value of the tissue and segmentation of the region, and was exported as an igs file, then incorporated into Geomagic 12 for smoothing, meshing and fitting surface processing (Fig. 1).

Then the model was incorporated into the Creo Parametric 2.0. In this study, we used OsteoMED 2.0 HPS Y-plate system. Thus the cannulated screws with a diameter of $2.0 \mathrm{~mm}$ and Y-steel plate were fabricated using Creo Parametric 2.0. A model of ulnar head was established and stabilized with ulnar side plate and the dorsal side plate respectively according to the practical surgical method with no interfragmentary gap (Fig. 2). The implant material was modeled as Titanium Alloy Ti6Al4V with material constants: Elastic Modulus E [GPa] 110; Poisson's ratio $\mu 0.33$.

Subsequently, the models were incorporated into ANSYS Workbench 15.0 for meshing and cut the fracture line of ulna head fracture described by Paksima[10]. When there are more than two geometric models, the relative relationship between the models should be set according to the actual situation, so we set the contact setting to binding relation in this report. (Fig. 3) 
The bone was defined with linear elastic material properties using Young's modulus of $17 \mathrm{GPa}$ for cortical bone and 1.5 GPa for cancellous bone. Poisson's ratio for both cortical and cancellous bones was 0.3 [16]. The elastic modulus and Poisson's ratio of various structural materials were shown in Table 1. The three-dimensional model of cortical bone and cancellous bone was developed by Boolean operation, and the proximal femoral bone model was built re-assembly.

Table 1

The maximum Von Mises peak stresses on fixation plate

\begin{tabular}{|lllll|}
\hline & $\begin{array}{l}\text { dorsal-side plate } \\
\text { (2 screws) }\end{array}$ & $\begin{array}{l}\text { dorsal-side } \\
\text { plate } \\
\text { (3 screws) }\end{array}$ & $\begin{array}{l}\text { ulnar-side plate } \\
\text { (2 screws) }\end{array}$ & $\begin{array}{l}\text { ulnar-side plate } \\
\text { (3 screws) }\end{array}$ \\
\hline $20 \mathrm{~N}$ axial compression & $392.53 \mathrm{MPa}$ & $397.17 \mathrm{MPa}$ & $383.90 \mathrm{MPa}$ & $313.25 \mathrm{MPa}$ \\
\hline $50 \mathrm{~N}$ axial compression & $981.31 \mathrm{MPa}$ & $992.93 \mathrm{MPa}$ & $958.80 \mathrm{MPa}$ & $636.35 \mathrm{MPa}$ \\
\hline $1 \mathrm{~N} \mathrm{~m}$ torsion moments & $201.05 \mathrm{MPa}$ & $158.10 \mathrm{MPa}$ & $192.08 \mathrm{MPa}$ & $151.94 \mathrm{MPa}$ \\
\hline
\end{tabular}

\section{Loading Force Settings}

In vivo loading conditions in the human DRUJ have not been completely discovered. Bernal et al. [17] found that the mean grip force was $18.6 \mathrm{~N}$ while performing a daily-life activity by measuring different subjects through wearable capacitive pressure sensors in the fingers. Putnam et al.[18] reported that each $10 \mathrm{~N}$ of grip force would transmit $26 \mathrm{~N}$ of force through the distal ulna metaphysis in the wrist neutral position. If the wrist was no longer in extension and ulnar deviation owing to the variation of hand position during power grip, the amount of force through the distal ulna metaphysis would reduce. In order to simulate forces acting on the ulnar and the osteosynthesis material during daily-life activity in subjects who underwent reconstructive surgery, we applied three loading conditions to each model, viz. axial compression 20N (Fig. 4A), 50N (Fig. 4B), and torsion moments $1 \mathrm{~N} \mathrm{~m}$ (Fig. 4C)[19].

\section{Evaluation Criteria Of The System}

First, the maximum displacement of the fracture end of the model was measured. Second, four models' von Mises Stress (VMS) distribution and peak VMS of both the fixation plates and the internal fixation system were observed[20]. These parameters were used to capture the mechanical factors involved in the fixation stability and fracture healing[21].

\section{Results}

\section{Von Mises Stress (VMS) Distribution}


The VMS patterns of the three loading settings in four fixation systems were shown in Fig. 5. The stress values of ulnar-side plate were lower than those of dorsal-side plate. Obvious concentration of stress on 4 models in 3 loading settings was found near the fracture line. The VMS patterns of three loading settings in four implant plates were shown in Fig. 6 and the maximum Von Mises peak stresses on fixation plate were recorded in Table 1. Thus, the maximum Von Mises peak stresses of ulnar-side fixation plate was lower, which indicated the ulnar-side fixation plate could smoothly transfer the load to the proximal cortical bone. The peak stress in fixation system under torsion moments could be reduced by adding a screw in the middle hole of the ulnar head. Although it was decreased only in ulna side plate fixation under axial compression, it may evidently concentrate the stress on the middle screw.

\section{Fracture Displacement Changes}

The model displacement patterns of three loading settings in four fixation systems were shown in Fig. 7. The values of model displacement in ulna-side fixation group were lower than those in the dorsal-side fixation group. When adding a screw in the middle hole of the ulnar head, the displacement in fixation system could be reduced. The maximum displacement of the 4 models was shown in Table 2.

Table 2

The maximum displacement of the 4 models

\begin{tabular}{|lllll|}
\hline & $\begin{array}{l}\text { dorsal-side plate } \\
\text { (2 screws) }\end{array}$ & $\begin{array}{l}\text { dorsal-side plate } \\
\text { (3 screws) }\end{array}$ & $\begin{array}{l}\text { ulnar-side plate } \\
\text { (2 screws) }\end{array}$ & $\begin{array}{l}\text { ulnar-side plate } \\
\text { (3 screws) }\end{array}$ \\
\hline 20N axial compression & $0.403 \mathrm{~mm}$ & $0.386 \mathrm{~mm}$ & $0.301 \mathrm{~mm}$ & $0.248 \mathrm{~mm}$ \\
\hline $50 \mathrm{~N}$ axial compression & $1.007 \mathrm{~mm}$ & $0.966 \mathrm{~mm}$ & $0.837 \mathrm{~mm}$ & $0.431 \mathrm{~mm}$ \\
\hline $1 \mathrm{~N} \mathrm{~m}$ torsion moments & $0.176 \mathrm{~mm}$ & $0.137 \mathrm{~mm}$ & $0.156 \mathrm{~mm}$ & $0.043 \mathrm{~mm}$ \\
\hline
\end{tabular}

\section{Discussion}

The static stability of the DRUJ is achieved by the bony congruity between the sigmoid notch of the radius and the ulnar head and by the ligaments which hold the joint together[22]. Part of the ligaments constitute the main stabilizer of DRUJ, which run from the fovea of the ulnar head to the dorsal and palmar edges of the sigmoid notch on the distal radius. [23-25]. The distal interosseous membrane (DIOM) of the forearm acts as a secondary soft tissue stabilizer of DRUJ. DIOM originates from the distal ulna $54 \mathrm{~mm}$ (on average) proximal to the ulnar head and runs distally to insert on the dorsal inferior rim of the sigmoid notch of the radius, which is at the terminal of the central band of the interosseous membrane [26-28]. Therefore, when the ulnar head breaks, the ligament will lose its stable attachment point, resulting in the instability of DRUJ. Distal ulnar metaphyseal fracture can be deemed as a fracture ranging from the ulnar neck to within $5 \mathrm{~cm}$ of the distal dome of the ulnar head and the high incidence of it is related to osteoporosis[29]. Since 2000, with the development of internal fixation technology and increasing aging population, people's requirements for the recovery of wrist joint function are gradually 
improved. More and more surgeons choose open reduction and internal fixation to treat unstable distal ulnar fractures[30,31]. Palmer and Werner[32] showed up to $42 \%$ of force passing through the ulna, in which axial force passing down the ulnar head fracture end was closer to $20 \%[32]$. The above studies indicated that the loss of the ulna head would disrupt the biomechanics and load-bearing capacity of the DRUJ. Therefore, the demand for internal fixation treatment become higher owing to the biomechanical characteristics of ulna head fracture.

However, the number of reported cases and literatures is rather sparse, which is mostly limited by the low incidence, merely 5-6\%, of distal radius fractures accompanied by a distal ulnar metaphyseal fracture.[3]. At present, it remains plenty of controversies around the treatment of distal ulnar head fracture. It is challenging to perform an internal fixation of distal ulnar metaphyseal fractures because the distal fracture fragment is small, comminuted, osteoporotic, covered with articular surface over a $270^{\circ}$ arc and surgical exposure of the distal ulna for hardware placement raises the possibility to damage the dorsal sensory branch of the ulnar nerve[33]. The most widely used fixation methods are dorsal micro-locking plate and anatomical hook plate, but it remains unclear about their merits and drawbacks and mechanical properties. Although the hook plate conforms to the ulnar anatomical structure of the distal ulna, there are few screw holes in the head which are arranged vertically, and the screw placement is limited during operation. On the other hand, the locking plate has more screw holes and the characteristics of pre bending. Considering that the horizontal arrangement of screws has higher anti rotation ability, we propose a method of placing the micro-locking plate on the ulnar side. Nevertheless, limited by the number of clinical cases, retrospective study is difficult to carry out. Therefore, a new way of analysis is urgently demanded.

Nowadays, thanks to the latest development of finite element model generation, such as improved quality of CT imaging, segmentation algorithm and computing rate, the accuracy of finite element modeling has been greatly elevated[34]. With the maturity of technology, 3D finite element analysis (FEA) can simulate the biomechanical analysis of complex orthopedic diseases and get rid of the limitation of the lack of cases. In this study, we chose to use FEA to figure out whether placing the ulnar side locking plate had better biomechanical properties than the current choice of the dorsal side locking plate. We hope the mechanical results of this study provide experimental guidance to its application in clinical surgeries.

As shown in Table 2, the ulnar-side locking plate models provided more stable fixation than the dorsalside models and the stability increased with the augment of head screws. Figures 5 and 6 illustrated that the stress of the four fixation systems was concentrated at the fracture line. Both the stress concentration zone and the maximum displacement were decreased in ulnar-side locking plate fixation. As shown in Table 1, under torsion moments, the peak VMS of the ulnar-side fixation models are lower than the dorsalside one, and it reduced as adding the additional ulnar head screw, which evidently indicated the antitorsion function of the horizontally arranged ulnar head screw. Under the axial loading, the peak VMS increased on the dorsal-side fixation models and concentrated at the middle additional screw, while it decreased on the ulnar-side fixation models. The results mentioned above indicated that ulnar-side locking plate fixation provided better stability, resulting in the lower stress distribution on the plate and 
greater security of the fixation system. Ulnar-side plate fixation could generate a rigid, stable mechanism and provide a strong resistance ability to counter compression and torsion effect. Adding the additional screw enabled the fixation models to generate a better stability, but concentrated the stress on the middle screw, which will guide the design of subsequent plate improvement. This study is the first FEA comparing the mechanical efficiency of dorsal-locking plate and ulnar-side locking plate in the fixation of ulnar head fracture. However, with the limitation of no experimental validation was conducted and no soft tissue structure was built in the models, the application of these fixation plates still requires more research.

This finite element simulation may facilitate the further mechanical research and give guidance to the treatment of the ulnar head fracture clinically.

\section{Conclusions}

In conclusion, our study indicated that plating locking plate on ulnar side had lower stress distribution on the plate and better stability than on dorsal side in ulnar head fracture fixation. Adding the additional screw on the ulnar head could reduce the displacement of the fixation system and increase the stability of the fixation system. This study requires clinical confirmation as to its practicality in the treatment of ulnar head fracture.

\section{Abbreviations}

DRUJ, Distal radius and ulna joint; CT, Computed tomography; VMS, Von Mises Stress; DIOM, Distal interosseous membrane; FEA, Finite element analysis;

\section{Declarations}

\section{Ethics approval and consent to participate}

This study was approved by the ethics committee of Shanghai East Hospital affiliated to Tongji University School of Medicine. Informed consent was obtained from all the participants.

\section{Consent for publication}

Not applicable

\section{Availability of data and materials}

The datasets used and/or analyzed during the current study are available from the corresponding author on reasonable request.

\section{Competing interests}


The authors declare that they have no competing interests.

\section{Funding}

This study was supported by the Natural Science Foundation of China (81704101), the Emergency and Critical Care Medicine project of Pudong (PWYgf2018-05) and the Project of Shanghai Science and Technology Commission (17411968400).

\section{Authors' contributions}

Guixin Sun and Yue Zhang designed the study. Yue Zhang and Qin Shao performed the data analysis, and review and submission and was a major contributor in writing the manuscript. Chensong Yang and Yang Yu performed finite element analysis. Changqin Ai performed the manuscript redaction and review. Di Zhou performed the collection of radiography data. Guixin Sun approved the final version of the manuscript. All authors have read and approved the final manuscript.

\section{Acknowledgements}

The authors would like to acknowledge Haojun Liu for his help in the picture production.

\section{References}

1. Shaaban $\mathrm{H}$, et al. the distal radioulnar joint as a load-bearing mechanism-a biomechanical study 1 1 No benefits in any form have been received or will be received by a commercial party related directly or indirectly to the subject of this article. The Journal of Hand Surgery. 2004;29(1):85-95.

2. Naito K, et al. Assessment of dorsal instability of the ulnar head in the distal radioulnar joint: comparison between normal wrist joints and cases of ruptured extensor tendons. Eur J Orthop Surg Traumatol. 2016;26(2):161-6.

3. Biyani A, Simison AJ, Klenerman L. Fractures of the distal radius and ulna. J Hand Surg Br. 1995;20(3):357-64.

4. Boretto JG, et al. Comparative Study of Internal Fixation of the Ulna and Distal Ulna Resection in Patients Older Than 70 Years With Distal Radius and Distal Metaphyseal Ulna Fractures. Hand (N Y). 2019;14(4):540-6.

5. McKee MD, et al. Nonunion of distal radial fractures associated with distal ulnar shaft fractures: a report of four cases. J Orthop Trauma. 1997;11(1):49-53.

6. Nemeth N, Bindra RR. Fixation of distal ulna fractures associated with distal radius fractures using intrafocal pin plate. J Wrist Surg. 2014;3(1):55-9.

7. Fernandez DL, Ring D, Jupiter JB. Surgical management of delayed union and nonunion of distal radius fractures. J Hand Surg Am. 2001;26(2):201-9.

8. Ring D. Nonunion of the distal radius. Hand Clin. 2005;21(3):443-7. 
9. Ruchelsman DE, Raskin KB, Rettig ME. Outcome following acute primary distal ulna resection for comminuted distal ulna fractures at the time of operative fixation of unstable fractures of the distal radius. Hand (New York, N.Y.), 2009. 4(4): p. 391-396.

10. Paksima N, et al, Fracture of the Distal Ulna Metaphysis in the Setting of Distal Radius Fractures. Bull Hosp Jt Dis (2013), 2017. 75(2): p. 104-108.

11. Ring $D$, et al. Condylar blade plate fixation of unstable fractures of the distal ulna associated with fracture of the distal radius 11 No benefits in any form have been received or will be received by a commercial party related directly or indirectly to the subject of this article. The Journal of Hand Surgery. 2004;29(1):103-9.

12. Dennison DG. Open Reduction and Internal Locked Fixation of Unstable Distal Ulna Fractures With Concomitant Distal Radius Fracture. The Journal of Hand Surgery. 2007;32(6):801-5.

13. Hazel A, Nemeth N, Bindra R. Anatomic Considerations for Plating of the Distal Ulna. J Wrist Surg. 2015;4(3):188-93.

14. Lee SK, et al. Distal ulna hook plate fixation for unstable distal ulna fracture associated with distal radius fracture. Orthopedics. 2012;35(9):e1358-64.

15. Nunez FA Jr, et al. Distal ulna hook plate: angular stable implant for fixation of distal ulna. Journal of wrist surgery. 2013;2(1):87-92.

16. Cun Y, et al., Traditional and bionic dynamic hip screw fixation for the treatment of intertrochanteric fracture: a finite element analysis. Int Orthop, 2020.

17. Cepria-Bernal J, et al. Grip force and force sharing in two different manipulation tasks with bottles. Ergonomics. 2017;60(7):957-66.

18. Putnam MD, et al. Distal radial metaphyseal forces in an extrinsic grip model: Implications for postfracture rehabilitation. The Journal of Hand Surgery. 2000;25(3):469-75.

19. Caiti G, et al. Biomechanical considerations in the design of patient-specific fixation plates for the distal radius. Med Biol Eng Comput. 2019;57(5):1099-107.

20. Tianye $L$, et al. Finite element analysis of different internal fixation methods for the treatment of Pauwels type III femoral neck fracture. Biomed Pharmacother. 2019;112:108658.

21. Zhang H, et al., Finite Element Analysis of Different Double-Plate Angles in the Treatment of the Femoral Shaft Nonunion with No Cortical Support opposite the Primary Lateral Plate. Biomed Res Int, 2018. 2018: p. 3267107.

22. Garcia-Elias M. Soft-tissue anatomy and relationships about the distal ulna. Hand Clin. 1998;14(2):165-76.

23. af Ekenstam F, Hagert CG. The distal radio ulnar joint. The influence of geometry and ligament on simulated Colles' fracture. An experimental study. Scand J Plast Reconstr Surg. 1985;19(1):27-31.

24. Palmer AK. Triangular fibrocartilage complex lesions: a classification. J Hand Surg Am. 1989;14(4):594-606. 
25. Shaw JA, Bruno A, Paul EM. Ulnar styloid fixation in the treatment of posttraumatic instability of the radioulnar joint: a biomechanical study with clinical correlation. J Hand Surg Am. 1990;15(5):71220.

26. Moritomo H. The distal interosseous membrane: current concepts in wrist anatomy and biomechanics. J Hand Surg Am. 2012;37(7):1501-7.

27. Moritomo $\mathrm{H}$. The distal oblique bundle of the distal interosseous membrane of the forearm. J Wrist Surg. 2013;2(1):93-4.

28. Moritomo H, Omori S. Influence of ulnar translation of the radial shaft in distal radius fracture on distal radioulnar joint instability. J Wrist Surg. 2014;3(1):18-21.

29. Logan AJ, Lindau TR. The management of distal ulnar fractures in adults: a review of the literature and recommendations for treatment. Strategies Trauma Limb Reconstr. 2008;3(2):49-56.

30. Chen WP, et al. Selection of fixation devices in proximal femur rotational osteotomy: clinical complications and finite element analysis. Clin Biomech (Bristol Avon). 2004;19(3):255-62.

31. Azad A, et al. Epidemiological and Treatment Trends of Distal Radius Fractures across Multiple Age Groups. J Wrist Surg. 2019;8(4):305-11.

32. Palmer AK, Werner FW. Biomechanics of the distal radioulnar joint. Clin Orthop Relat Res, 1984(187): p. 26-35.

33. Richards TA, Deal DN. Distal ulna fractures. J Hand Surg Am. 2014;39(2):385-91.

34. Poelert S, et al., Patient-specific finite element modeling of bones. Proceedings of the Institution of Mechanical Engineers, Part H: Journal of Engineering in Medicine, 2012. 227(4): p. 464-478.

\section{Figures}




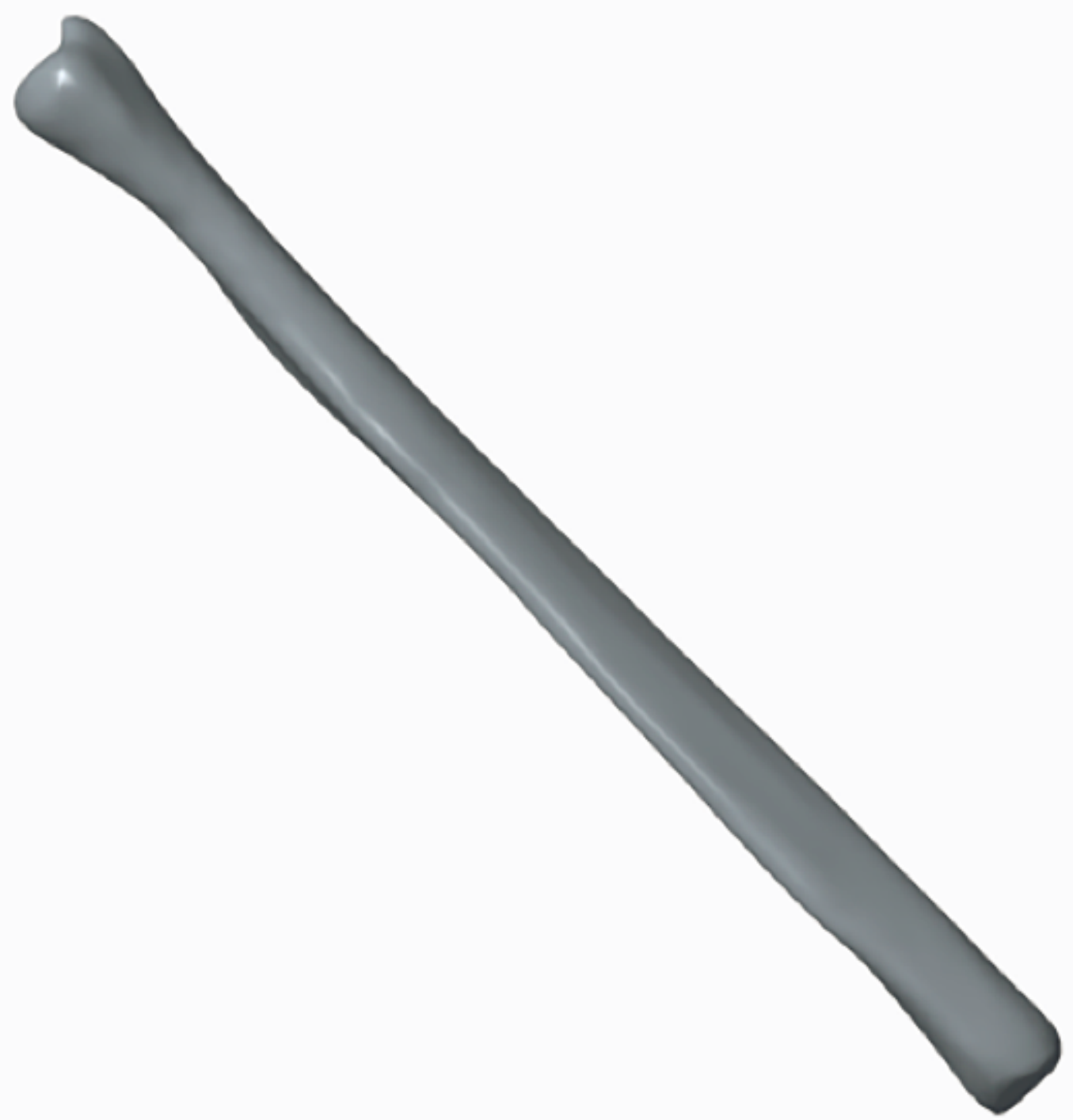

Figure 1

3D model of the right ulna built by Geomagic 12 . 

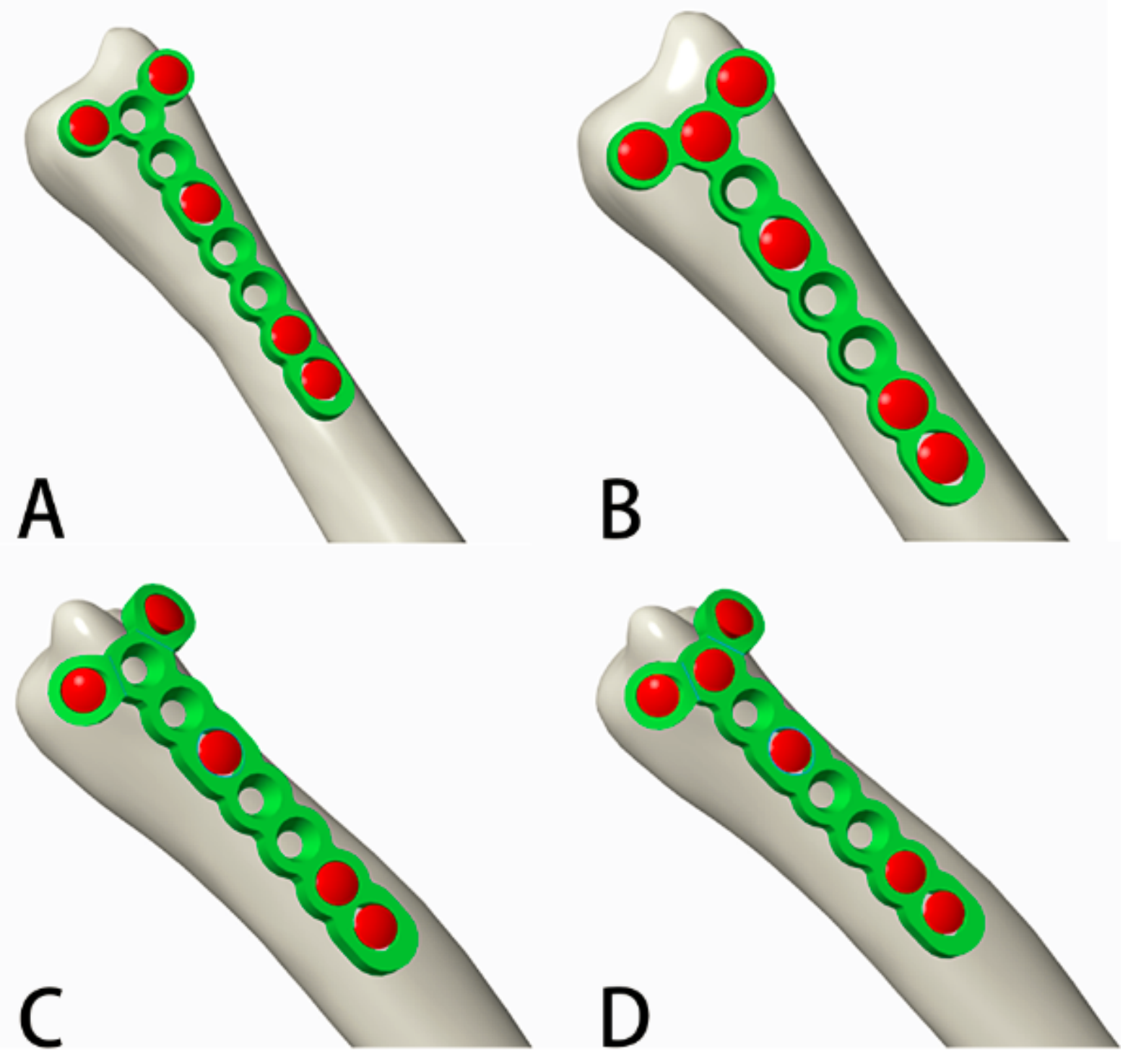

Figure 2

(A) Model of dorsal side locking plate with two distal screws. (B) Model of dorsal side locking plate with three distal screws. (C) Model of ulnar side locking plate with two distal screws. (D) Model of ulnar side locking plate with three distal screws. 

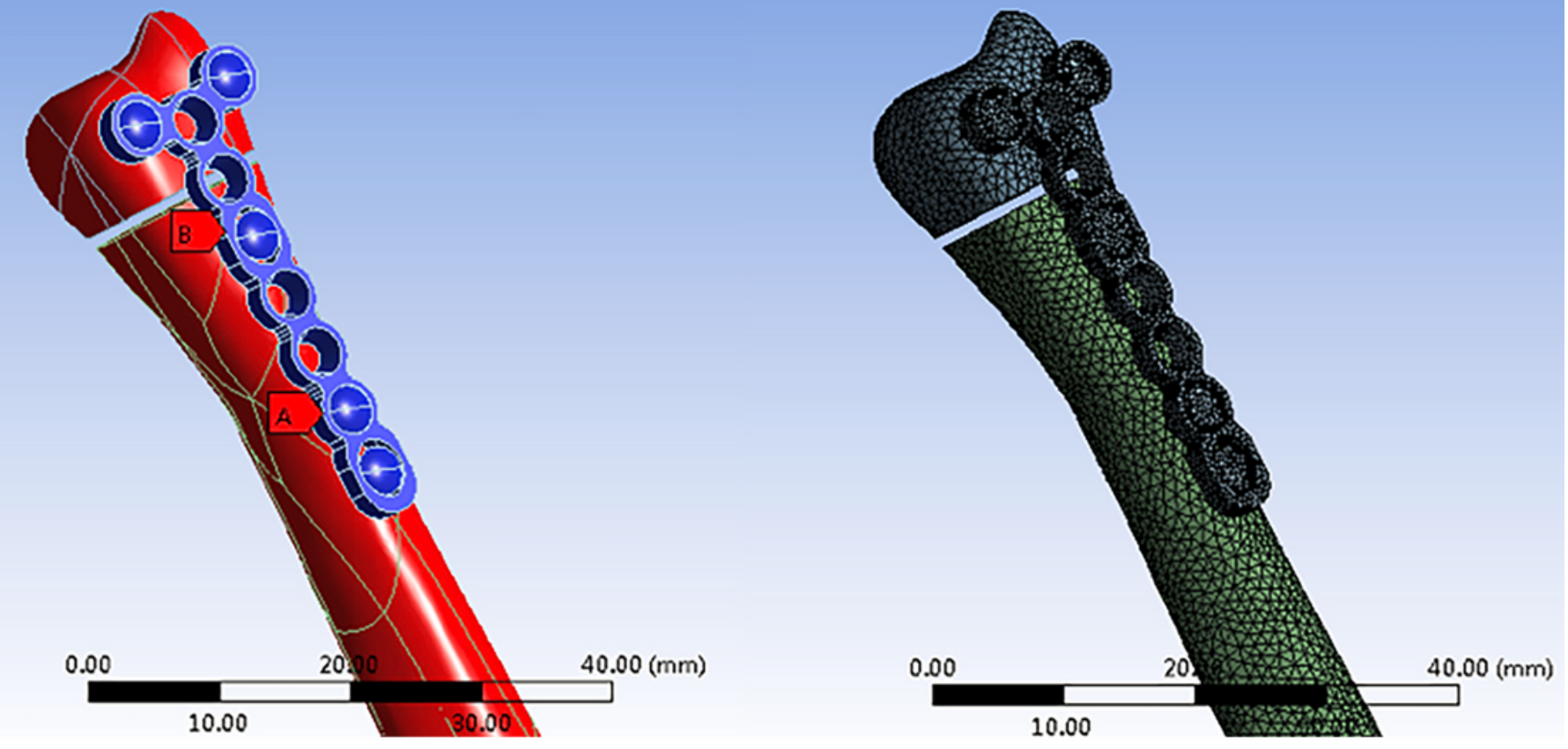

Figure 3

Stablishing the internal fixation models of ulnar head fracture and importing the models into Abaqus software for meshing.
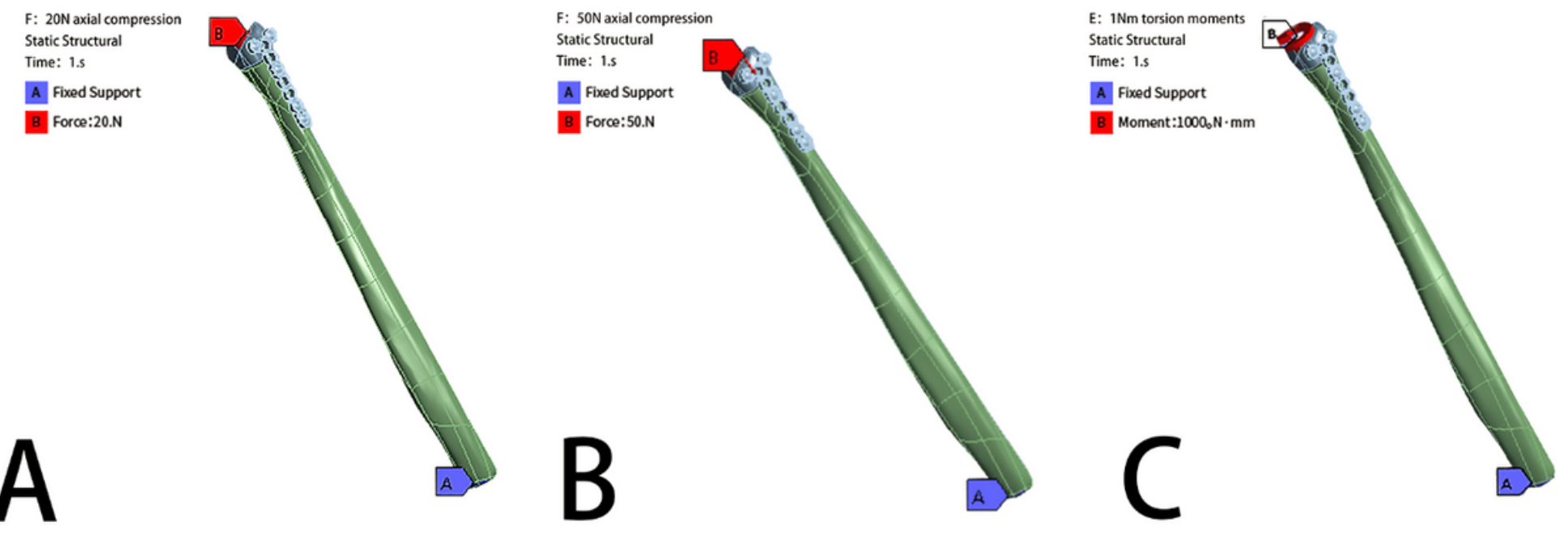

Figure 4

Loading force settings:(A) Axial compression 20N. (B) Axial compression 50N. (C) Torsion moments $1 \mathrm{Nm}$. 
F: 20N aisil compression Equivalent Stress

Unit: MPo

392.53 Max

$\square_{142.29}^{392.53}$

${ }^{94.53}$

70.649
-46768

22.837

2.5442
$0.001352 \mathrm{M}$

A

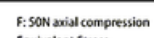

Equivalent Stress

Type: Equivatent

Time: 1

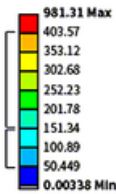

B

F: INm torsion moments

Equivalent Stress

Unit: $M P$ :

$\square_{79.164}^{201.05 \text { Max }}$

$\left[\begin{array}{l}-79.164 \\ -69.269 \\ -49.974 \\ -49.976\end{array}\right.$

49.478
-39.583

$\begin{array}{r}23.688 \\ -19.792 \\ \hline\end{array}$

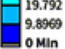

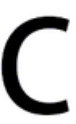

Figure 5

Von Mises Stress distribution of four different fixation systems under three loading settings. (A) $20 \mathrm{~N}$ axial compression group. (B) $50 \mathrm{~N}$ axial compression group. (C) $1 \mathrm{Nm}$ torsion moments group. 


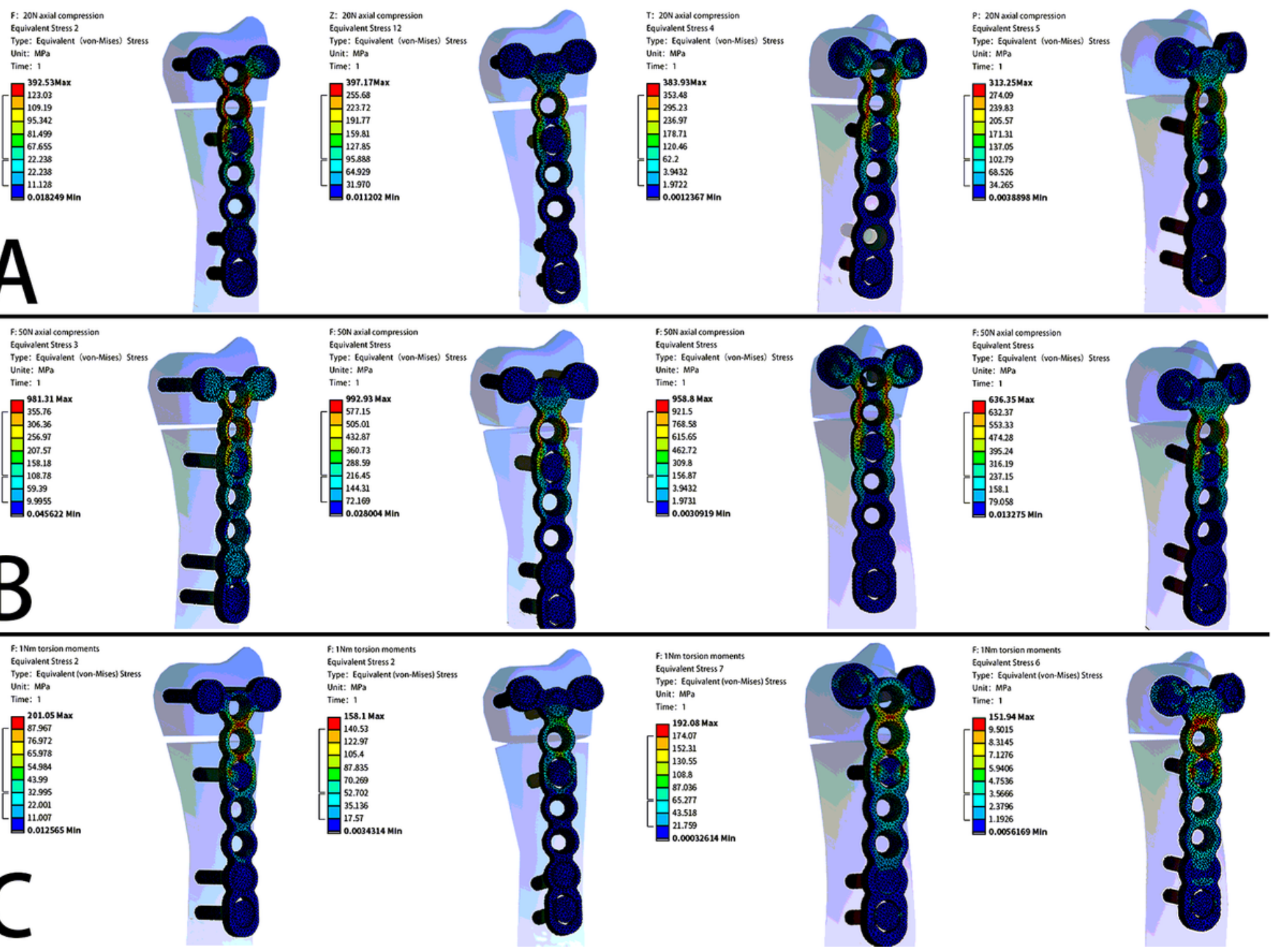

Figure 6

Von Mises Stress distribution of four different fixation plates under three loading settings. (A) $20 \mathrm{~N}$ axial compression group. (B) $50 \mathrm{~N}$ axial compression group. (C) $1 \mathrm{Nm}$ torsion moments group. 


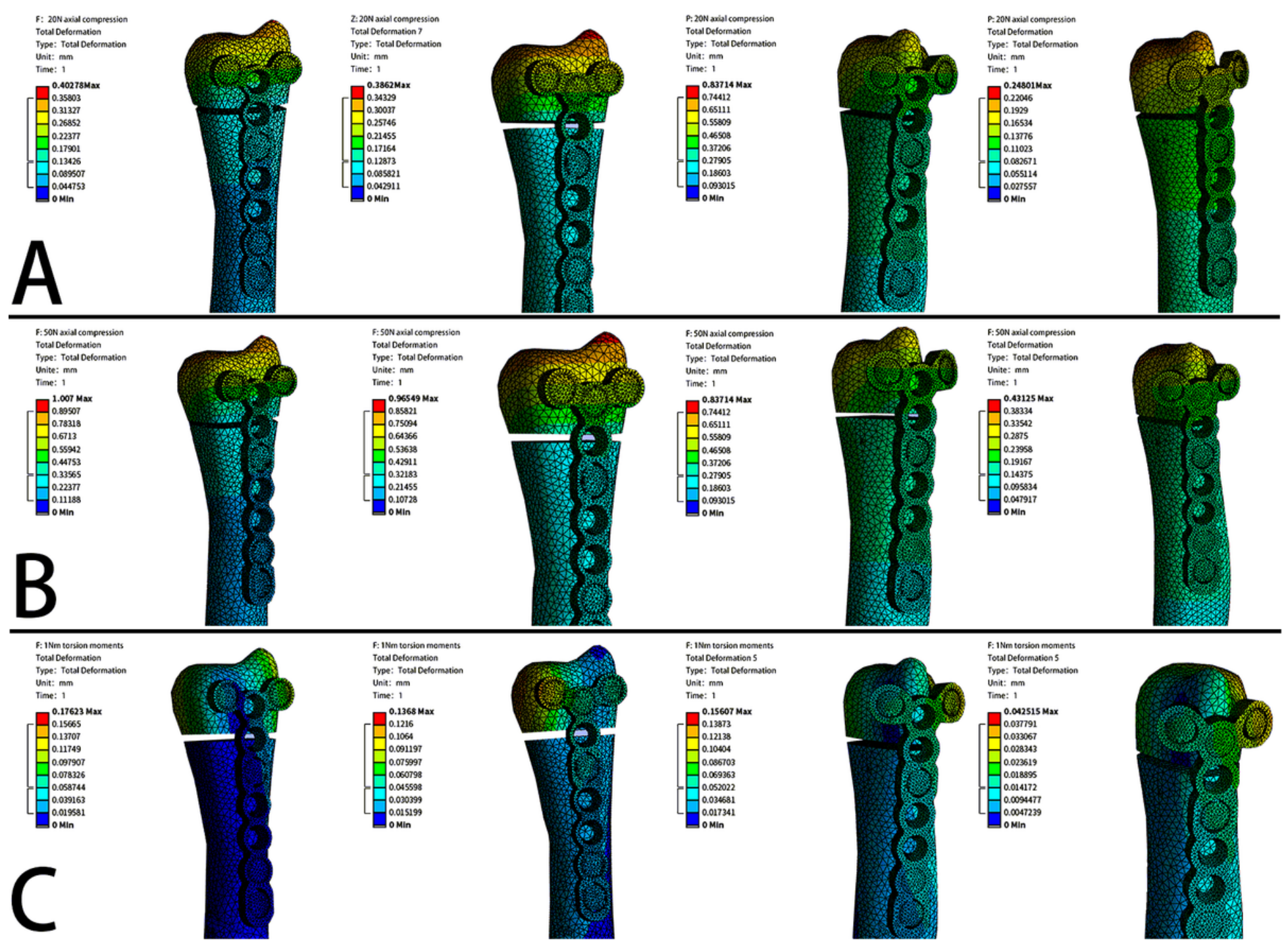

Figure 7

The model displacement patterns of four different fixation plates under three loading settings. (A) $20 \mathrm{~N}$ axial compression group. (B) $50 \mathrm{~N}$ axial compression group. (C) $1 \mathrm{Nm}$ torsion moments group. 